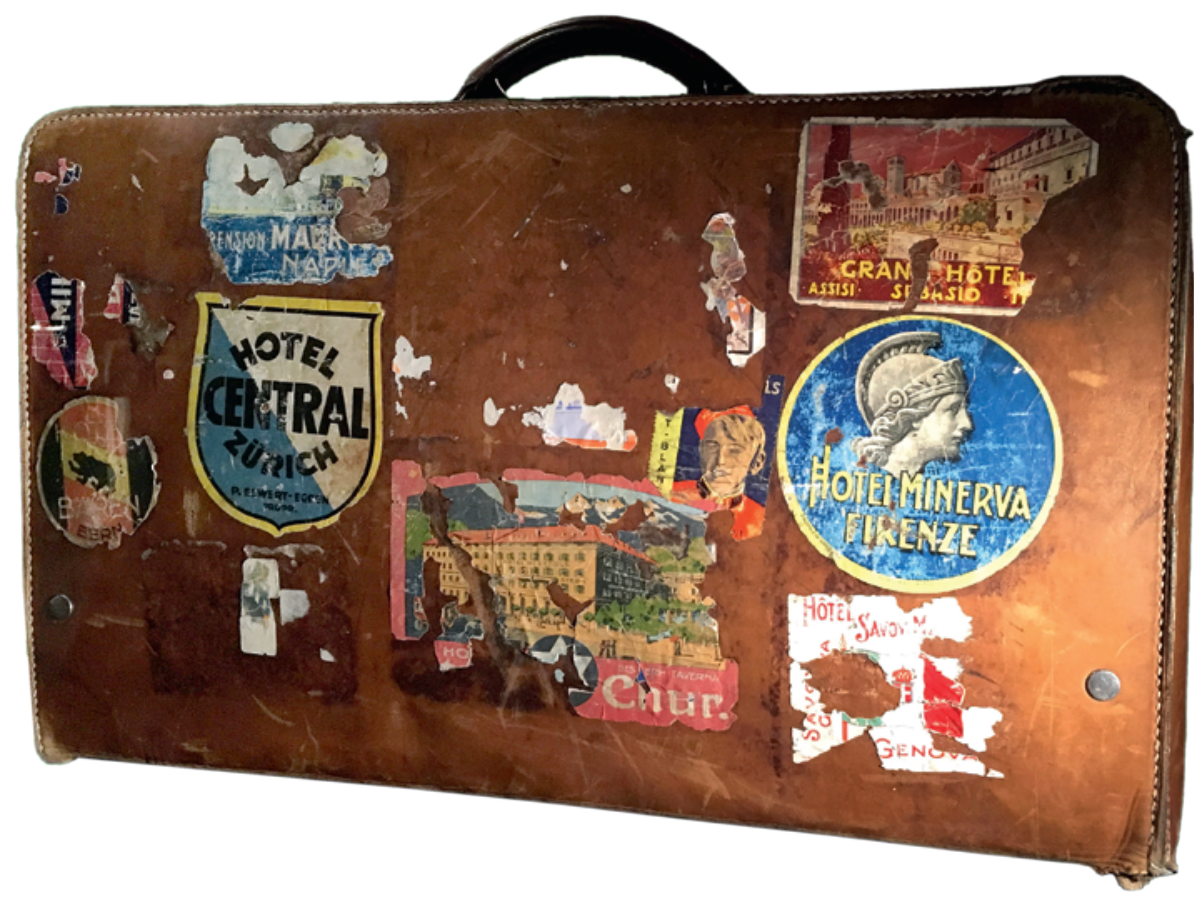

Reisekoffer von Alberto Giacometti, im Hotel 7132

Therme Vals.

\title{
Mit dem Koffer ins Spital
}

\section{Iris Ritzmann}

Prof. Dr. med. et lic. phil, Universität Zürich, Mitglied der Redaktion Medizingeschichte

Gerade mal 30 auf 50 cm misst der Reisekoffer aus Leder. Er ist mit zahlreichen farbigen Stickern übersät. Von der Belle Epoque bis in die 1960er Jahre hinein schmückten Reisende ihr Gepäck mit Klebebildern bekannter Hotels. Für die Gasthäuser wurden die Koffer so zu Werbeträgern, für die Besitzer zu Protzobjekten, Logbüchern oder einfach Erinnerungsalben. Besonders beliebt waren farbige Aufkleber mit exotischen Motiven oder grossen Schiffen, die den Wohlstand der Kofferbesitzer bezeugten. Der kleine braune Reisekoffer dagegen ist neben Zürich, Bern und Chur offenbar vor allem in italienischen Städten herumgekommen: «Milano», "Assisi», «Genova» und «Firenze» ist zu entziffern. Es sind Städte, die durch ihre Kunstwerke und Bauten bekannt sind und von Künstlern bereist wurden und werden. Effektiv stammt das lederne Gepäckstück von einem Patienten und Künstler. Sein Besitzer hiess Alberto Giacometti, wobei der Koffer ursprünglich Giacomettis Vater gehört hatte.

In einer Dezembernacht des Jahres 1965 reisen der Reisekoffer und mit ihm Alberto Giacometti von Paris nach Chur. Dieses Mal geht es nicht ins Bergell, um die Familie über die Festtage zu besuchen. Nein, der Bildhauer und Maler kämpft mit gesundheitlichen
Schwierigkeiten. Herz- und Kreislaufprobleme, chronische Bronchitis und völlige Erschöpfung lassen ihn ins Kantonsspital Chur eintreten. Für die Tage der erhofften Erholung und Genesung muss der kleine Reisekoffer genügen.

Giacometti hat eigentlich gar keine Zeit für eine Behandlung oder gar einen Kuraufenthalt. Und erst recht keine Zeit zu sterben. In seinem Pariser Atelier steht eine weit gediehene Tonfigur. Der Fotograf Eli Lotar hat seinem Freund Alberto Modell gestanden. Doch Giacometti stirbt nach einer Brustpunktion im Januar 1966 im Kreis seiner Angehörigen. Die Figur vollendet Giacomettis jüngerer Bruder Diego, giesst sie in Bronze und stellt sie auf Albertos Grab, von wo sie später entwendet wird. Den Reisekoffer aber nimmt sein jüngster Bruder Bruno aus dem Spital mit. Als dieser im Alter von 104 Jahren stirbt, wird der Koffer zusammen mit anderen Erbstücken zugunsten des Kinderspitals Kantha Bopha versteigert. Nun reist der Koffer erneut nach Graubünden, dieses Mal in die Therme Vals, einen Ort der Gesundung und Erholung, wo er noch heute in der Hotellobby zu sehen ist.

Foto

Iris Ritzmann, 2019 